\title{
Robust On-line Rotor Time Constant Estimation for Induction Machines
}

\author{
Anno $\mathrm{Yoo}^{\dagger}$ \\ ${ }^{\dagger}$ LSIS Co., Ltd., Anyang, Korea
}

\begin{abstract}
This paper proposes an on-line rotor time constant estimation strategy for indirect field oriented induction machines. The performance of the indirect field oriented control is dependent especially on the rotor time constant whose value varies according to the temperature. The proposed method calculates the difference between the nominal rotor time constant and the real value from the $\mathrm{d}$ - and q-axis integration terms of a proportional integral (PI) current regulator and the demanded voltages of the induction machine to regulate the current in the steady state. Because the proposed strategy has a simple structure and is available in wide speed and torque ranges, the proposed method can be easily used in the industrial field. The effectiveness of proposed strategy is verified with simulations and a $7.5 \mathrm{~kW}$ experimental setup.
\end{abstract}

Key words: Indirect Field Oriented Control (IFOC), Induction machine, On-line rotor time constant estimation

\section{INTRODUCTION}

In addition to their long history, induction machines are still widely used in many applications such as automation, electric/hybrid vehicles, and general purpose drives because of their simple structure, low cost, robustness, improved efficiency and reduced size [1]-[4].

Induction machines can be driven with various control methods such as Constant Air-gap Flux Operation (V/f), Direct Torque Control (DTC), Field Oriented Control (FOC), and so on [5]-[7], [11]-[13]. Among the above control methods, the Indirect Filed Oriented Control (IFOC) is widely used in the industrial field due to its simplicity.

Fig. 1 shows a simplified control diagram of the IFOC for an induction machine. As shown in the figure, an accurate rotor time constant which is defined as $T_{r}=L_{r} / R_{r}$ is required for calculating the slip frequency, and the calculated slip frequency is proportional to the inverse value of the rotor time constant. Where the flux current is controlled as a constant value, the rotor time constant, which is a temperature dependent parameter, has a slow variation time-wise and results in a severe torque error [8]. In some applications such as winding and printing machines, a tension which is regulated by

Manuscript received Jun. 13, 2014; accepted Jul. 14, 2014

Recommended for publication by Associate Editor Kwangwoon Lee.

${ }^{\dagger}$ Corresponding Author: ayoo@1sis.biz

Tel: +82-31-450-7693, LSIS Co., Ltd.

LSIS Co., Ltd., Korea precise torque control is required, and the performance is dependent on variations of the rotor time constant.

There have been several previous studies to update the time-varying rotor time constant [8]-[17]. In [8], [14] and [15], the rotor flux is estimated for updating the rotor time constant. In this case, the accuracy of the estimated rotor flux was dependent on the stator resistance which was another parameter varying according to the temperature. In [9], an additional external circuit was installed to measure the accurate output pole voltage of the inverter in order to calculate the rotor time constant. All of the output pole voltages of the voltage source inverter were measured when both the upper and lower switches were open, and a specific PWM technique was considered. Due to cost issues, it would be hard to utilize an external circuit. In [10], a recursive parameter estimation method was used in order to update the rotor time constant. Although a recursive parameter update scheme has been widely used, it was necessary to have the transient inductance value accurately measured off-line. In [11] and [12], the rotor time constant was estimated by a reactive power calculation. The performance of proposed scheme was independent from variations of the stator resistance. However, the calculated reactive power might be inaccurate in low speed and low torque operations, and the performance might be dependent on the output frequency. In [13], the dynamic characteristics of the speed controller were investigated for estimating the rotor resistance. This method changed the d-axis current reference 


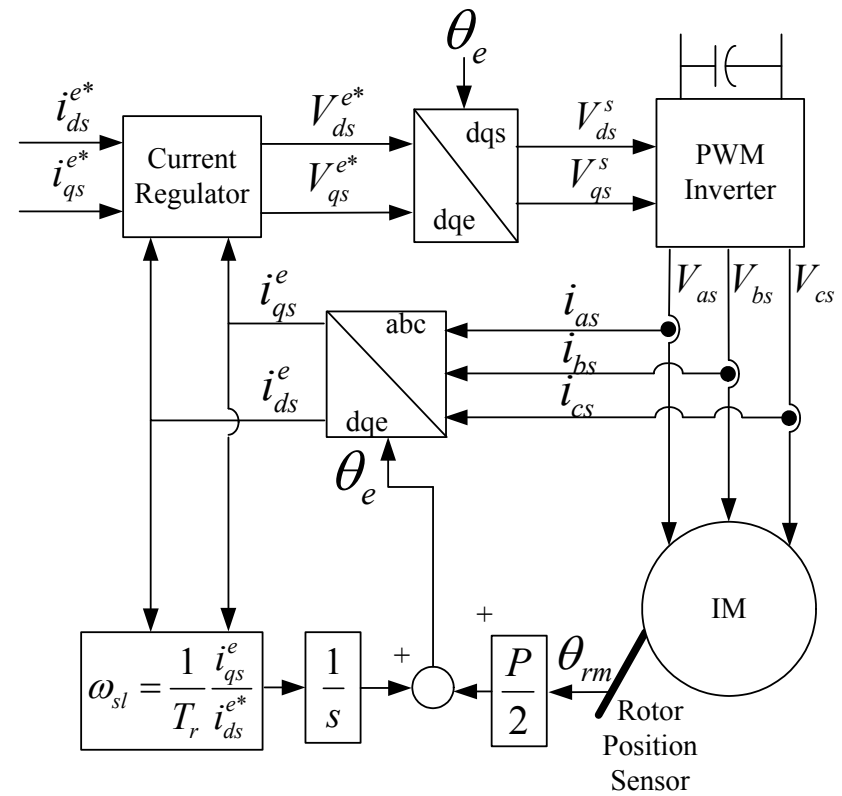

Fig. 1. Block diagram of indirect field oriented control.

to induce the output of the speed controller and to inspect the variations of the output of the speed controller. However, this strategy could only be used in the speed control mode, and it took a relative long time to settle down because an interaction procedure was needed.

This paper proposes a novel on-line rotor time constant for indirect field oriented induction machines. The proposed method is easy to implement and the performance is independent of variations of the stator resistance. In addition, the proposed strategy works well even in low speed and low torque operations. These advantages can be obtained with the integral term of a Proportional Integral (PI) current regulator including a feed-forward scheme. When the $\mathrm{d}$ - and $\mathrm{q}$-axis currents are regulated well in the steady state, the current regulator takes a charge of the parameter mismatch. With the characteristics of the PI current regulator, the time-varying rotor time constant can be updated correctly. The effectiveness of proposed method is verified by simulations and experimental results obtained with a $7.5 \mathrm{~kW}$ induction machine prototype.

\section{FEED-BACK CONTROL SYSTEM AND CONTROLLER}

Fig. 2 shows the simplified feed-back control system where a feed-forward term is included for disturbance rejection. In Fig. 2, ' $i(\mathrm{~s})$ ', ' $o(\mathrm{~s})$ ', ' $C(\mathrm{~s})$ ', ' $P(\mathrm{~s})$ ', ' $v(\mathrm{~s})$ ', ' $\mathrm{v}_{\mathrm{fff}}(\mathrm{s})$ ', and ' $U_{c}(\mathrm{~s})$ ' are the reference, the output signal, the controller, the plant, disturbance term, the feed-forward term, and the output of the controller, respectively.

The transfer function for the output signal is deduced as (1).

$$
o(s)=\frac{C(s) P(s)}{1+C(s) P(s)} i(s)+\frac{P(s)}{1+C(s) P(s)}\left(v(s)-v_{f f}(s)\right)
$$

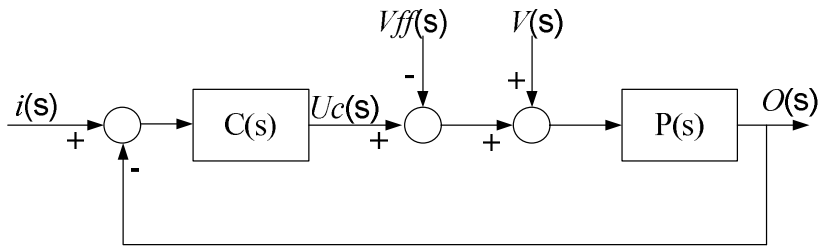

Fig. 2. Simplified control block diagram.

In (1), the second term on the right hand side can be ignored when the disturbance rejection is performed perfectly and the control system can be considered as a disturbance-free system. If the disturbance is not canceled out perfectly, the output signal is affected by the error of the disturbance rejection in order to regulate the output signal.

In addition, the output of the controller is given as (2).

$$
U_{c}(s)=\frac{C(s)}{1+C(s) P(s)} i(s)-\frac{C(s) P(s)}{1+C(s) P(s)}\left\{v(s)-v_{f f}(s)\right\}
$$

In a general control system, the multiplication of the controller and the plant is usually much larger than ' 1 ', and the second term of (2) can be simplified. With the above assumption, the output signal can be deduced as (3).

$$
U_{c}(s) \cong \frac{C(s)}{1+C(s) P(s)} i(s)-\left\{v(s)-v_{f f}(s)\right\}
$$

In addition, the output of the controller can be defined as (4) when the regulation is performed well.

$$
U_{c}(s)=C(s)\{i(s)-o(s)\}=\frac{o(s)}{P(s)}+v_{f f}(s)-v(s)
$$

In (4), the output value of the controller, the feed-forward term and the output signal are known values, and the average error between the real plant, including the disturbance and the nominal plant, can be calculated easily.

\section{MODELING OF AN INDUCTION MACHINE AND A PI CURRENT REGULATOR WITH A FEED-FORWARD TERM}

Fig. 3 shows an equivalent circuit of an induction machine in the synchronous reference frame. As shown in Fig. 3, the dand q-axis equivalent circuits are coupled with each other, and the d- and q-axis stator and rotor voltages and fluxes of the induction machine in the synchronous reference frame can be given in (5) to (12).

$$
\begin{gathered}
V_{d s}^{e}=R_{s} i_{d s}^{e}+p \lambda_{d s}^{e}-\omega_{e} \lambda_{q s}^{e} \\
V_{q s}^{e}=R_{s} i_{q s}^{e}+p \lambda_{q s}^{e}+\omega_{e} \lambda_{d s}^{e} \\
0=R_{r} i_{d r}^{e}+p \lambda_{d r}^{e}-\omega_{s l} \lambda_{q r}^{e} \\
0=R_{r} i_{q r}^{e}+p \lambda_{q r}^{e}+\omega_{s l} \lambda_{d r}^{e} \\
\lambda_{d s}^{e}=L_{s} i_{d s}^{e}+L_{m} i_{d r}^{e} \\
\lambda_{q s}^{e}=L_{s} i_{q s}^{e}+L_{m} i_{q r}^{e} \\
\lambda_{d r}^{e}=L_{m} i_{d s}^{e}+L_{r} i_{d r}^{e}
\end{gathered}
$$




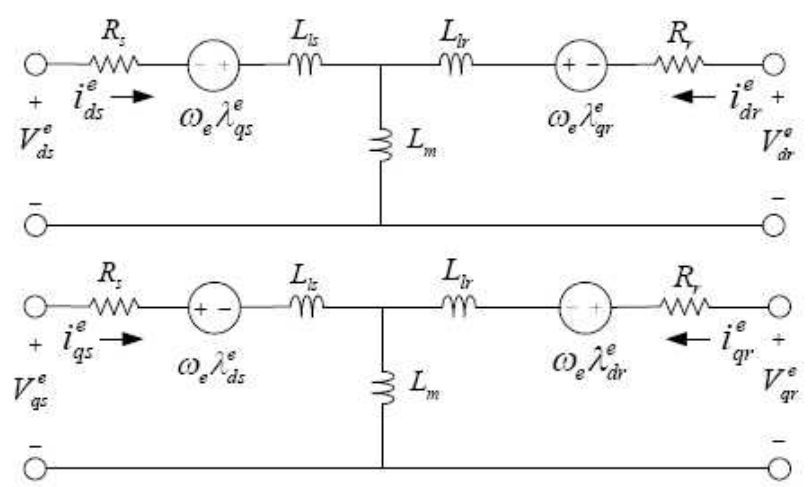

Fig. 3. Equivalent circuit of induction machine in the synchronous reference frame.

$$
\lambda_{q r}^{e}=L_{m} i_{q s}^{e}+L_{r} i_{q r}^{e}
$$

where $V_{d s}^{e}, V_{q s}^{e}, V_{d r}^{e}, V_{q r}^{e}, i_{d s}^{e}, i_{q s}^{e}, i_{d r}^{e}, i_{q r}^{e}, \lambda_{d s}^{e}$, $\lambda_{q s}^{e}, \lambda_{d r}^{e}, \lambda_{q r}^{e}, R_{s}, R_{r}, L_{s}, L_{r}, L_{m}, \omega_{e}$, and $\omega_{s l}$ are the $\mathrm{d}$ - and $\mathrm{q}$-axis stator voltages, the $\mathrm{d}$ - and q-axis rotor voltages, the $\mathrm{d}$ - and q-axis stator currents, the $\mathrm{d}$ - and q-axis rotor currents, the d- and q-axis stator fluxes, and the d- and q-axis rotor fluxes in the synchronous reference frame, along with the stator resistance, rotor resistance, stator inductance, rotor inductance, mutual inductance, rotor flux angular speed, and slip frequency, respectively.

With the above voltage and flux equations, the d- and q-axis stator voltages in the synchronous reference frame are derived as (13) and (14).

$$
\begin{gathered}
V_{d s}^{e}=R_{s} i_{d s}^{e}+\sigma L_{s} \frac{d i_{d s}^{e}}{d t}-\omega_{r} \sigma L_{s} i_{q s}^{e}-\sigma L_{s} \frac{1}{T_{r}} \frac{i_{q s}^{e 2}}{i_{d s}^{e}} \\
V_{q s}^{e}=R_{s} i_{q s}^{e}+\sigma L_{s} \frac{d i_{q s}^{e}}{d t}+\omega_{r} L_{s} i_{d s}^{e}+L_{s} \frac{1}{T_{r}} i_{q s}^{e}
\end{gathered}
$$

where $\sigma L_{s}$ is the transient inductance, which is defined as $\sigma L_{s}=L_{s}-\frac{L_{m}^{2}}{L_{r}}$. In addition, $\omega_{r}$ is the electrical rotor speed, and $T_{r}$ is the rotor time constant.

The third terms at the right side of (13) and (14) can be considered as back-EMF components because their magnitude is proportional to the rotor speed. In addition, the last terms are defined as the coupling terms.

A Proportional Integral (PI) current regulator with feed-forward terms in the synchronous reference frame is widely used in IFOC due to its simplicity and robustness. For improving the performance of the current regulation of IFOC, it is necessary to decouple the back-EMFs and the coupling terms with a feed-forward scheme. The d- and q-axis output voltages of the current regulator are given as (15) and (16). The $\mathrm{d}$ - and q-axis feed-forward terms for decoupling can be given as (17) and (18) considering the voltage equations of (13) and (14).

$$
\begin{aligned}
& V_{d s_{-} \text {out }}^{e}=\left(K_{P}+\frac{K_{I}}{s}\right)\left(i_{d s}^{e^{*}}-i_{d s}^{e}\right)+V_{d s_{-} f f}^{e} \\
& V_{q s_{-} \text {out }}^{e}=\left(K_{P}+\frac{K_{I}}{s}\right)\left(i_{q s}^{e^{*}}-i_{q s}^{e}\right)+V_{q s_{-} f f}^{e} \\
& V_{d s_{-} f f}^{e}=-\omega_{r} \sigma \hat{L}_{s} i_{q s}^{e}-\sigma \hat{L}_{s} \frac{1}{\hat{T}_{r}} \frac{i_{q s}^{e 2}}{i_{d s}^{e}} \\
& V_{q s_{-} f f}^{e}=\omega_{r} \hat{L}_{s} i_{d s}^{e}+\hat{L}_{s} \frac{1}{\hat{T}_{r}} i_{q s}^{e}
\end{aligned}
$$

where $K_{P}, K_{I}, i_{d s}^{e^{*}}, i_{d s}^{e}, i_{q s}^{e^{*}}, i_{q s}^{e}, V_{d s_{-} \text {out }}^{e}, V_{q s_{-} \text {out }}^{e}$, $V_{d s_{-} f f}^{e}$, and $V_{q s_{-} f f}^{e}$ are the proportional gain, the integral gain, the d-axis current reference, the d-axis feedback current reference, the q-axis current reference, the q-axis feedback current, the output voltage of the $\mathrm{d}$ - and q-axis, and the feed-forward voltage of the $\mathrm{d}$ - and q-axis. In addition, '^^${ }^{\wedge}$ refers to the nominal values.

When the machine parameters are accurate, the back-EMF and coupling terms are decoupled, and the transfer functions of the d- and q-axis currents are given as (19) and (20).

$$
\begin{aligned}
& \frac{i_{d s}^{e}}{i_{d s}^{e^{*}}}=\frac{K_{P} s+K_{I}}{\sigma L_{s} s^{2}+\left(R_{s}+K_{P}\right) s+K_{I}} \\
& \frac{i_{q s}^{e}}{i_{q s}^{e^{*}}}=\frac{K_{P} s+K_{I}}{\sigma L_{s} s^{2}+\left(R_{s}+K_{P}\right) s+K_{I}}
\end{aligned}
$$

In addition, if the proportional and the integral gains are set as (21) and (22), the transfer functions of the d- and q-axis currents can be designed as a $1^{\text {st }}$ order low pass filter with the designed bandwidth, as shown in (23) and (24).

$$
\begin{gathered}
K_{P}=\sigma L_{s} \omega_{c} \\
K_{I}=R_{s} \omega_{c} \\
\frac{i_{d s}^{e}}{i_{d s}^{e^{*}}}=\frac{\omega_{c}}{s+\omega_{c}} \\
\frac{i_{q s}^{e}}{i_{q s}^{e^{*}}}=\frac{\omega_{c}}{s+\omega_{c}}
\end{gathered}
$$

where $\omega_{c}$ is the designed cut-off frequency of the current regulator.

\section{PHENOMENA WITH AN INACCURATE ROTOR TIME CONSTANT}

The performance of the IFOC is especially dependent on the accuracy of the rotor time constant even though the rotor speed is measured exactly. In the case of IFOC, the slip frequency 
and generated torque in the steady state are given as (25) and (26).

$$
\begin{gathered}
\omega_{s l}=\frac{1}{T_{r}} \frac{i_{q s}^{e}}{i_{d s}^{e}} \\
T_{e}=\frac{3}{2} \frac{P}{2} \frac{L_{m}^{2}}{L_{e}} i_{d s}^{e} i_{q s}^{e}=K_{T} i_{d s}^{e} i_{q s}^{e}
\end{gathered}
$$

where $\mathrm{P}$ is the number of poles, and $K_{T}$ is the torque constant.

Fig. 4 demonstrates the d- and q-axis current domain in the synchronous reference frame when the rotor time constant is inaccurate. In Fig. 4, the ' $\wedge$ ' means the estimated axis with an inaccurate rotor time constant. When the nominal rotor time constant is larger than the real one, the estimated d- and q-axis currents are lagging and vice versa. If the estimated frame is leading in the steady state, the real d- and q-axis currents are given as (27) and (28).

$$
\begin{aligned}
& i_{d s}^{e}=\hat{i}_{d s}^{e} \cos \varphi-\hat{i}_{q s}^{e} \sin \varphi \\
& i_{q s}^{e}=\hat{i}_{q s}^{e} \cos \varphi+\hat{i}_{d s}^{e} \sin \varphi
\end{aligned}
$$

where $\varphi$ is the angle between the real axis and the estimated one. That is, $\varphi=\int\left(\frac{1}{T_{r}} \frac{i_{q s}^{e}}{i_{d s}^{e}}-\frac{1}{\hat{T}_{r}} \frac{\hat{i}_{q s}^{e}}{\hat{i}_{d s}^{e}}\right) d t$.

By the definition, the slip frequency and the generated torque are given as (29) and (30) in the steady state.

$$
\begin{gathered}
\omega_{s l}=\frac{1}{T_{r}} \frac{\hat{i}_{q s}^{e} \cos \varphi+\hat{i}_{d s}^{e} \sin \varphi}{\hat{i}_{d s}^{e} \cos \varphi-\hat{i}_{q s}^{e} \sin \varphi} \\
T_{e}=K_{T}\left[\hat{i}_{d s}^{e} \hat{i}_{q s}^{e} \cos 2 \varphi+\left(\frac{\hat{i}_{d s}^{e 2}-\hat{i}_{q s}^{e 2}}{2}\right) \sin 2 \varphi\right]
\end{gathered}
$$

When the d-axis current is controlled as a constant value, the slip frequency can be changed with an inaccurate rotor time constant and the demanded torque cannot be obtained.

\section{PROPOSED ON-LINE Rotor TIME CONSTANT ESTIMATION STRATEGY}

\section{A. Proposed Strategy}

As mentioned in Section II, the output of a controller reflects the error between the nominal parameters and the real ones when the control performs well in the steady state. In this section, a novel on-line rotor time constant estimation strategy is shown considering the output of the current regulator.

In the steady state, the current variation can be ignored and the demanded $\mathrm{d}$ - and q-axis voltages to regulate given $\mathrm{d}$ - and q-axis currents can be approximated as (31) and (32).

$$
V_{d s, s t e a d y}^{e}=R_{s} i_{d s}^{e}-\omega_{r} \sigma L_{s} i_{q s}^{e}-\sigma L_{s} \frac{1}{T_{r}} \frac{i_{q s}^{e 2}}{i_{d s}^{e}}
$$

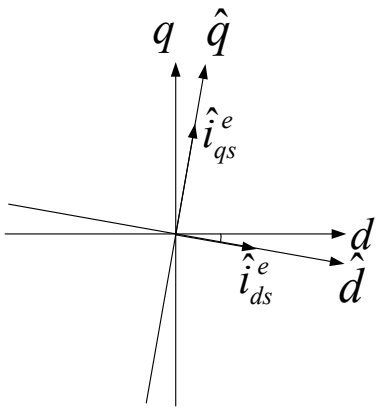

(a)

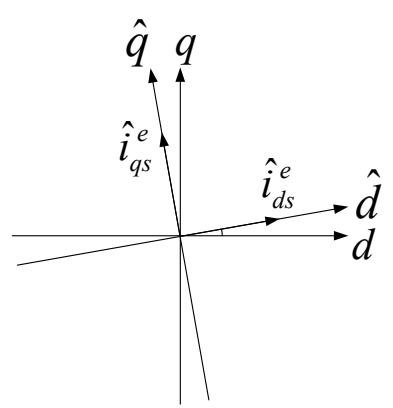

(b)
Fig. 4. d- and q-axis current in the synchronous reference frame with the inaccurate rotor time constant. (a) $\hat{T}_{r}>T_{r}$. (b) $\hat{T}_{r}<T_{r}$.

$$
V_{q s, s t e a d y}^{e}=R_{s} i_{q s}^{e}+\omega_{r} L_{s} i_{d s}^{e}+L_{s} \frac{1}{T_{r}} i_{q s}^{e}
$$

In addition, the output voltage of the current regulator can be approximated as the output voltage of an integrator in the average sense.

$$
\begin{gathered}
V_{d s_{-} \text {out }, \text { steady }}^{e} \cong \frac{K_{I}}{s}\left(i_{d s}^{e^{*}}-i_{d s}^{e}\right)+V_{d s_{-} f f}^{e} \\
V_{q s_{-} \text {out }, \text { steady }}^{e} \cong \frac{K_{I}}{s}\left(i_{q s}^{e^{*}}-i_{q s}^{e}\right)+V_{q s_{-} f f}^{e}
\end{gathered}
$$

When the inductance values such as $\sigma L_{s}$ and $L_{s}$ are accurate and the rotor speed can be exactly obtained with a rotor position sensor such as an encoder and resolver, the output voltage of the current regulator and the required voltage of the induction machine to regulate the current are matched in the steady state.

$$
\begin{aligned}
& V_{d s, \text { steady }}^{e}=V_{d s_{-} \text {out }, \text { steady }}^{e} \\
& V_{q s, \text { steady }}^{e}=V_{q s_{-} \text {out }, \text { steady }}^{e}
\end{aligned}
$$

With (35) and (36), the reflected parameters at the d- and q-axis current regulator can be derived as (37) and (38).

$$
\begin{aligned}
& M=\frac{K_{I}}{s}\left(i_{d s}^{e^{*}}-i_{d s}^{e}\right)=R_{s} \hat{i}_{d s}^{e}+\sigma L_{s}\left(\frac{1}{\hat{T}_{r}}-\frac{1}{T_{r}}\right) \frac{i_{q s}^{e 2}}{i_{d s}^{e}} \\
& N=\frac{K_{I}}{s}\left(i_{q s}^{e^{*}}-i_{q s}^{e}\right)=R_{s} \hat{i}_{q s}^{e}-L_{s}\left(\frac{1}{\hat{T}_{r}}-\frac{1}{T_{r}}\right) i_{q s}^{e}
\end{aligned}
$$

As shown in (37) and (38), the output voltage magnitude of the $\mathrm{d}$ - and q-axis current regulator can be decided with the voltage drop caused by the stator resistance and voltage error which is due to the difference between the real rotor time constant and the nominal one.

With the output voltages of the d- and q-axis current regulator, the error between the real rotor time constant and the nominal value can be easily calculated as follows:

$$
\left.\Delta \frac{1}{T_{r}}=\frac{1}{\hat{T}_{r}}-\frac{1}{T_{r}}=\frac{\hat{i}_{d s}^{e}}{\hat{i}_{q s}^{e}} \frac{\left(M \hat{i}_{q s}^{e}-N \hat{i}_{d s}^{e}\right)}{\left(\sigma \hat{i}_{q s}^{e 2}+L_{s} \hat{i}_{d s}^{e 2}\right.}\right)
$$




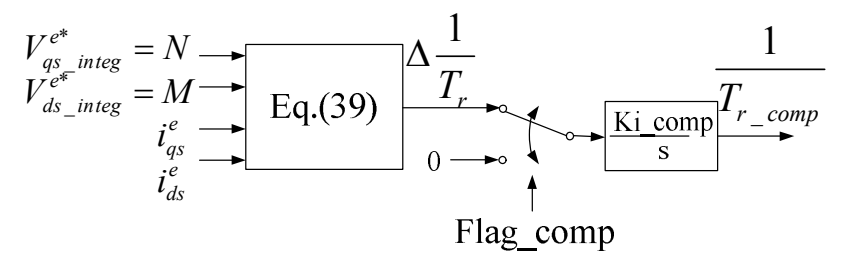

Fig. 5. Block diagram of rotor time constant error compensator.

In order to eliminate this error, a simple compensator is designed as shown in Fig. 5. The compensator is composed of an integrator with a specific gain, ' $K_{i \text { comp }}$ ' and 'Flag_comp' is a flag to decide whether the on-line tuning is operated or not. The specific gain, ' $K_{i \text { comp }}$ ', can be set while considering the convergence time of the proposed method. The variation of the rotor time constant is slow depending on the temperature, and a high specific gain may bring about large variations in the current. In order to get rid of large torque variations while identifying the rotor time constant, the specific gain should be set properly so that it takes into consideration the temperature variations around the test machine.

With the output of the compensator, the inverse value of the rotor time constant is updated as (40), and the slip frequency can be modified as (41).

$$
\begin{gathered}
\frac{1}{T_{r_{-} \text {updated }}}=\frac{1}{\hat{T}_{r}}+\frac{1}{T_{r_{-} \text {comp }}} \\
\omega_{\text {sl }}=\frac{1}{T_{r_{-} \text {updated }}} \frac{\hat{i}_{q s}^{e}}{\hat{i}_{d s}^{e}}
\end{gathered}
$$

The updated rotor time constant value of (40) is utilized for the feed-forward term of the current regulator. The proposed strategy can update the time-varying rotor time constant regardless of variations of the stator resistance, and it can be easily implemented.

A control block diagram of the proposed scheme is shown in Fig. 6. The output of the proposed scheme is utilized for calculating the rotor flux angle and for updating the feed-forward terms of the current regulator.

\section{B. Validity of the Proposed Strategy}

In this section, the validity of proposed on-line updating scheme is shown mathematically. With an inaccurate rotor time constant, the generated d- and q-axis voltages and currents in the synchronous reference frame can be transformed as (42) and (43).

$$
\begin{aligned}
& {\left[\begin{array}{c}
\hat{V}_{d s}^{e} \\
\hat{V}_{q s}^{e}
\end{array}\right]=R^{-1}(\theta)\left[\begin{array}{c}
V_{d s}^{e} \\
V_{q s}^{e}
\end{array}\right]} \\
& =R^{-1}(\theta)\left[\begin{array}{cc}
R_{s}+\sigma L_{s} p & -\omega_{e} \sigma L_{s} \\
\omega_{e} L_{s} & R_{s}+\sigma L_{s} p
\end{array}\right]\left[\begin{array}{c}
i_{d s}^{e} \\
i_{q s}^{e}
\end{array}\right]
\end{aligned}
$$

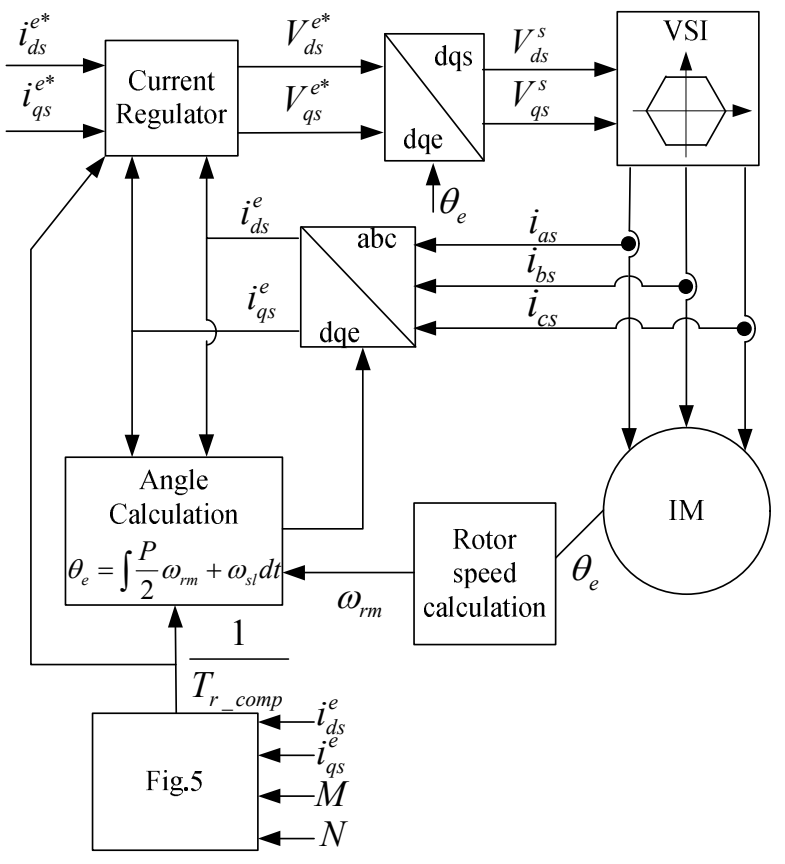

Fig. 6. Block diagram of IFOC with the proposed strategy.

$$
\left[\begin{array}{c}
i_{d s}^{e} \\
i_{q s}^{e}
\end{array}\right]=R(\theta)\left[\begin{array}{c}
\hat{i}_{d s}^{e} \\
\hat{i}_{q s}^{e}
\end{array}\right]
$$

where

$$
R(\theta)=\left[\begin{array}{cc}
\cos \varphi & \sin \varphi \\
-\sin \varphi & \cos \varphi
\end{array}\right]
$$

$$
R^{-1}(\theta)=\left[\begin{array}{cc}
\cos \varphi & -\sin \varphi \\
\sin \varphi & \cos \varphi
\end{array}\right] \text {. }
$$

The differential terms of (43) can be calculated as (44).

$$
\begin{aligned}
& {\left[\begin{array}{c}
\sigma L_{s} p i_{d s}^{e} \\
\sigma L_{s} p i_{q s}^{e}
\end{array}\right]} \\
& =\frac{d \varphi}{d t} \sigma L_{s} \frac{d R(\theta)}{d t}\left[\begin{array}{c}
\hat{i}_{d s}^{e} \\
\hat{i}_{q s}^{e}
\end{array}\right]+R(\theta)\left[\begin{array}{c}
\sigma L_{s} p \hat{i}_{d s}^{e} \\
\sigma L_{s} p \hat{i}_{q s}^{e}
\end{array}\right]
\end{aligned}
$$

where $\frac{d \varphi}{d t}=\omega_{e}-\hat{\omega}_{e}$.

With (42) and (43), the transformed d- and q-axis voltages can be rewritten as (45).

$$
\begin{aligned}
& {\left[\begin{array}{c}
\hat{V}_{d s}^{e} \\
\hat{V}_{q s}^{e}
\end{array}\right]=R^{-1}(\theta)\left[\begin{array}{cc}
R_{s}+\sigma L_{s} p & -\omega_{e} \sigma L_{s} \\
\omega_{e} L_{s} & R_{s}+\sigma L_{s} p
\end{array}\right] R(\theta)\left[\begin{array}{c}
\hat{i}_{d s}^{e} \\
\hat{i}_{q s}^{e}
\end{array}\right]} \\
& +R^{-1}(\theta) \frac{d \varphi}{d t} \sigma L_{s} \frac{d R(\theta)}{d t}\left[\begin{array}{c}
\hat{i}_{d s}^{e} \\
\hat{i}_{q s}^{e}
\end{array}\right] \\
& +R^{-1}(\theta) R(\theta)\left[\begin{array}{c}
\sigma L_{s} p \hat{i}_{d s}^{e} \\
\sigma L_{s} p \hat{i}_{q s}^{e}
\end{array}\right]
\end{aligned}
$$

In addition, the output voltages of the current regulator in the 
steady state can be approximated as follows:

$$
\begin{aligned}
\hat{V}_{d s}^{e} & =\left(K_{P}+\frac{K_{I}}{s}\right)\left(i_{d s}^{e^{*}}-i_{d s}^{e}\right)-\hat{\omega}_{e} \sigma L_{s} \hat{i}_{q s}^{e} \\
& \cong \frac{K_{I}}{s}\left(i_{d s}^{e^{*}}-i_{d s}^{e}\right)-\hat{\omega}_{e} \sigma L_{s} \hat{i}_{q s}^{e} \\
& =M-\hat{\omega}_{e} \sigma L_{s} \hat{i}_{q s}^{e} \\
\hat{V}_{q s}^{e} & =\left(K_{P}+\frac{K_{I}}{s}\right)\left(i_{q s}^{e^{*}}-i_{q s}^{e}\right)+\hat{\omega}_{e} L_{s} \hat{i}_{d s}^{e} \\
& \cong \frac{K_{I}}{s}\left(i_{q s}^{e^{*}}-i_{q s}^{e}\right)+\hat{\omega}_{e} L_{s} \hat{i}_{d s}^{e} \\
& =N+\hat{\omega}_{e} L_{s} \hat{i}_{d s}^{e}
\end{aligned}
$$

With (45), (46) and (47), the following equations can be obtained:

$$
\begin{aligned}
& M \hat{i}_{q s}^{e}-N \hat{i}_{d s}^{e}=\left(-\omega_{e} L_{s} i_{d s}^{e 2}+\hat{\omega}_{e} L_{s} \hat{i}_{d s}^{e 2}\right) \\
& +\left(-\omega_{e} \sigma L_{s} i_{q s}^{e 2}+\omega_{e} \sigma L_{s} \hat{i}_{d s}^{e 2}\right) \\
& +\left(\omega_{e} \sigma L_{s} \hat{i}_{d s}^{e 2}-\hat{\omega}_{e} \sigma L_{s} \hat{i}_{d s}^{e 2}\right)
\end{aligned}
$$

From the above equations, the left side term of (48) is convergent to 'zero' when the estimated angle matches the real one. When the rotor speed is measured and the slip frequency is calculated exactly with the proposed strategy, the angular speed of the rotor flux is accurate, and the error between the estimated current axis and the real one is zero. As a result, (39) is 'zero' with the proposed updating scheme regardless of variations of the stator resistnace.

\section{SimUlation AND EXPERIMENTAL RESUlTS}

To show the effectiveness of the proposed rotor time constant estimation, some simulations and experiments are carried out. The test machine is a $7.5 \mathrm{~kW}$ induction machine. Table I shows parameters of the tested machine.

Fig. 7 shows the simulation results when the induction machine is operated at $100 \mathrm{r} / \mathrm{min}$, the load torque is given as $20 \%$ of the rated value and the nominal stator resistance is set at $20 \%$ higher than the real value.

In the simulation, the specific gain, ' $K_{i \text { comp }}$, is 0.5 . In Fig. 7 (a), the initial nominal rotor time constant is $80 \%$ of the real value, and in Fig. 7(b), it is $120 \%$ of the real one. In this figure, the blue solid line is the real rotor time constant, and the green dotted line is the estimated value. At $5 \mathrm{sec}$, the proposed estimation strategy is started. As shown, the proposed strategy works well even though the stator resistance is inaccurate.

Fig. 8 demonstrates the performance of the proposed strategy when the induction machine is operated at $1500 \mathrm{r} / \mathrm{min}$ and the load torque is $90 \%$ of the rated value. In this figure, the stator resistance is given as $120 \%$ of the real value. After starting the proposed estimation at $5 \mathrm{sec}$, the estimated rotor time constant tracks the real value within $2 \mathrm{sec}$.
TABLE I

TEST MACHINE PARAMETERS

\begin{tabular}{|l|l|}
\hline Rated power & $7.5 \mathrm{~kW}$ \\
Rated Voltage & $220 \mathrm{~V}_{\mathrm{rms}}$ \\
Rated Current & $26.3 \mathrm{~A}_{\mathrm{rms}}$ \\
Rated Frequency & $60 \mathrm{~Hz}$ \\
Number of pole & 4 \\
Rated Slip Frequency & $70 \mathrm{r} / \mathrm{min}$ \\
Rotor Time Constant & $280 \mathrm{~ms}$ \\
Stator inductance & $31.32 \mathrm{mH}$ \\
Transient inductance & $2.81 \mathrm{mH}$ \\
Stator Resistance & $0.175 \Omega$ \\
No load current & $10.4 \mathrm{~A}_{\mathrm{rms}}$ \\
\hline
\end{tabular}

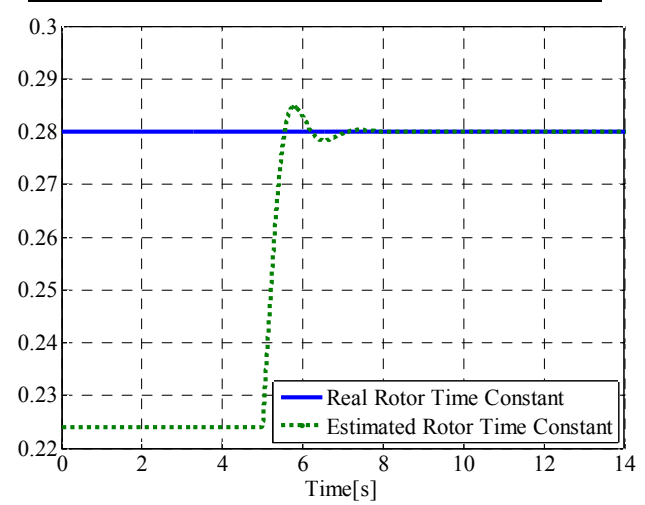

(a)

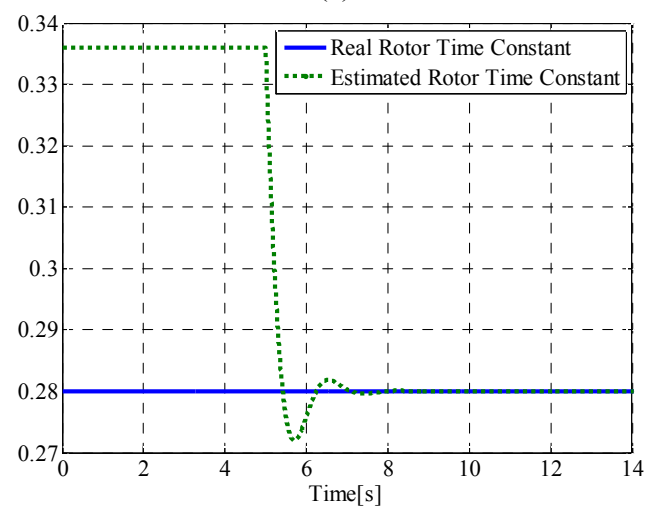

(b)

Fig. 7. Performance of proposed rotor time constant at $100 \mathrm{r} / \mathrm{min}$ and $20 \%$ load torque (simulation). (a) Initial nominal value is $80 \%$ of real value. (b) Initial nominal value is $120 \%$ of real value.

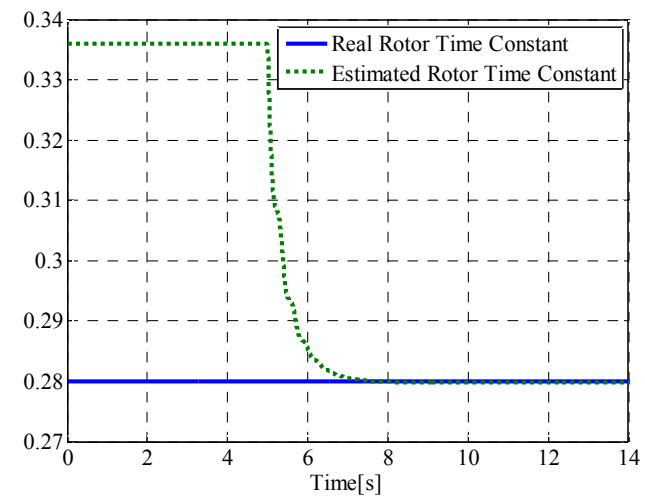

Fig. 8. Performance of proposed rotor time constant at 1,500r/min and $90 \%$ load torque (simulation). 


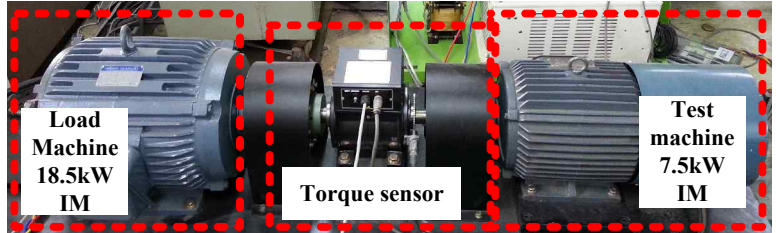

Fig. 9. Photo of experimental setup.

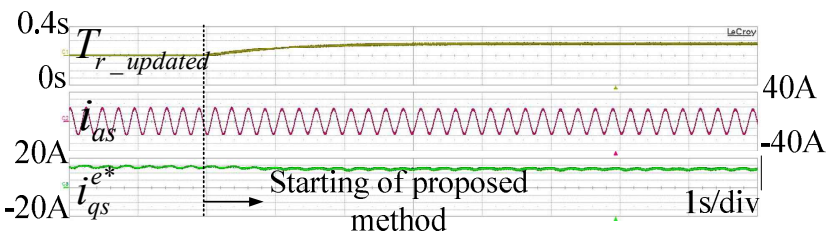

(a)

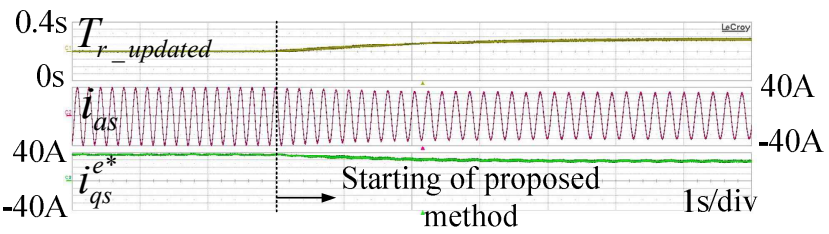

(b)

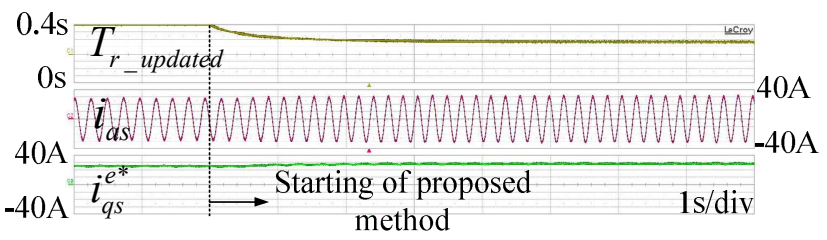

(c)

Fig. 10. Performance of proposed strategy at $100 \mathrm{r} / \mathrm{min}$. (a) Initial nominal rotor time constant of $0.2 \mathrm{~s}$ under $40 \%$ load torque. (b) Initial nominal rotor time constant of $0.2 \mathrm{~s}$ under $100 \%$ load torque. (c) Initial nominal rotor time constant of $0.4 \mathrm{~s}$ under $100 \%$ load torque.

Fig. 9 is a photo of the experimental setup where a $18.5 \mathrm{~kW}$ load machine is coupled with the test machine. In Fig. 10 and Fig. 11, the test machine is operated in the speed control mode and the load machine is operated in the torque control mode. In addition, the specific gain, ' $K_{\text {i comp }}$ ', is 1 in the experiments.

In Fig. 10, the induction machine is operated at $100 \mathrm{r} / \mathrm{min}$ and the nominal rotor time constant and load torque are variable in order to investigate the performacne of the proposed method at low speeds. In Fig. 10(a), the initail nominal rotor time constant is set to $200 \mathrm{~ms}$ under a $40 \%$ load torque. In addition, the initial rotor time constant is $200 \mathrm{~ms}$ under the $100 \%$ load condition in Fig. 10(b), and it is $400 \mathrm{~ms}$ in Fig. 10(c). After starting the proposed method, the rotor time constant is convergent to around $280 \mathrm{~ms}$ without any bumps. According to the initial value of the rotor time constant, the magnitude of the $\mathrm{q}$-axis current reference is changed to maintain the rotor speed.

In Fig. 11, the tested machine is run at $1500 \mathrm{r} / \mathrm{min}$ under the variable load condition. The initial rotor time constant is set to $200 \mathrm{~ms}$ and the rated load torque is given in Fig. 11(a). In addition, the initial rotor time constant is $400 \mathrm{~ms}$ under a $50 \%$

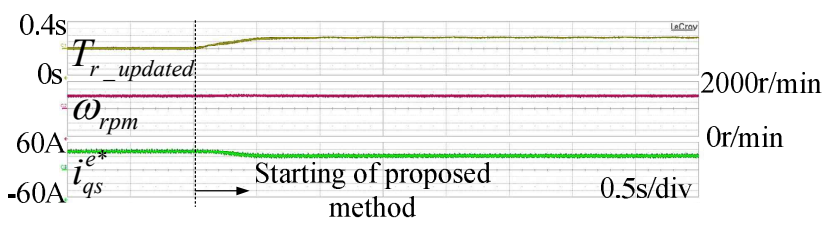

(a)

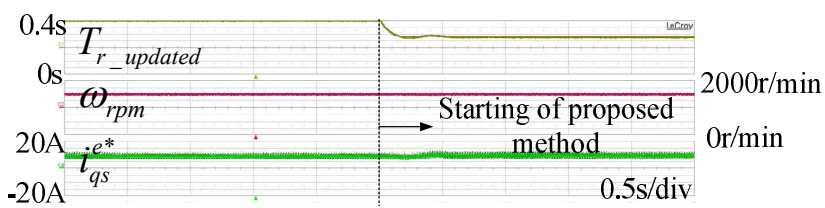

(b)

Fig. 11. Performance of proposed strategy at $1500 \mathrm{r} / \mathrm{min}$. (a) Initial nominal rotor time constant of $0.2 \mathrm{~s}$ under $100 \%$ load torque. (b) Initial nominal rotor time constant of $0.4 \mathrm{~s}$ under $50 \%$ load torque.

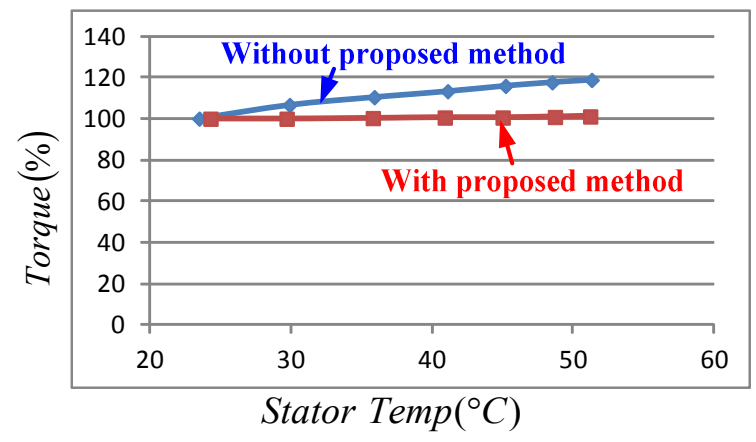

Fig. 12. Torque according to stator temperature.

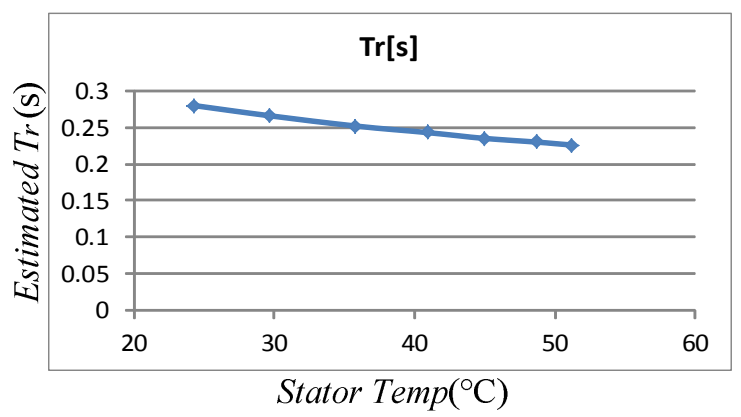

Fig. 13. Estimated rotor time constant according to stator temperature.

load condition. Within 2 seconds after the starting point of the proposed method, the estimated rotor time constant is converged to $280 \mathrm{~ms}$, and the q-axis current is changed according to the value of the estimated rotor time constant.

In Fig. 12 and Fig. 13, the test machine is operated in the torque control mode and the load machine is run in the speed control mode.

Fig. 12 demonstrates torque variations according to the stator temperature both with and without the proposed method. In Fig. 12, the test machine is operated in the constant torque control mode (100\% torque) and the load machine is run in the speed control mode (1000r/min) for an hour. As shown in Fig. 12 , the torque variation due to the stator temperature is less 
than $1.1 \%$ with the proposed method and almost $20 \%$ without the proposed method.

Fig. 13 shows the estimated rotor time constant with the proposed method. As shown in this figure, the estimated rotor time constant is reduced to $80 \%$ of the initial value as the stator temperature is increased.

With the simulation and experimental results, it can be concluded that the proposed on-line rotor time constant method works well through a wide operation region regardless of stator resistance variations.

\section{CONCLUSIONS}

This paper proposed an on-line rotor time constant estimation method for indirect field oriented induction machines. In general, an inaccurate rotor time constant, which is a time-varying value depending on temperature variations, degrades the performance of IFOC. To achieve a high-performance, the proposed strategy calculates the difference between the nominal rotor time constant value and the real one with the output voltage of a current regulator. In addition, the compensator is designed to update the rotor time constant value.

The proposed estimation scheme utilizes the required stator voltages to regulate the current in the synchronous reference frame and the integration terms of the current regulator. The integration terms of the current regulator reflect the mismatched rotor time constant, and this error value can be derived easily. The calculated rotor time constant error converges on zero with the designed compensator and the rotor time constant is updated simultaneously.

Even though the proposed scheme looks simple, the proposed strategy can work well in a wide operation range regardless of variations of the stator resistance. In addition, the proposed method works in both the speed control and the torque control. Experimental results with a $7.5 \mathrm{~kW}$ induction machine demonstrate that the torque variation due to the stator temperature is less than $1.1 \%$ with the proposed method.

\section{REFERENCES}

[1] F. Abrahamsen, F. Blaabjerg, J. K. Pedersen, P. Z. Grabowski, and P. Thogersen, "On the energy optimized control of standard and high-efficiency induction motors in CT and HVAC applications," IEEE Trans. Ind. Appl., Vol. 34, No. 4, pp. 822-831, Jul./Aug. 1998.

[2] J. M. Miller, A. R. Gale, P. J. McCleer, F. Leonardi, and J. H. Lang, "Starter-alternator for hybrid electric vehicle: Comparison of induction and variable reluctance machines and drives," in Proc IEEE-IAS, pp. 513-523, 1998.

[3] M. Naidu and J. Walters, "A 4-kW 42-V induction machine based automotive power generation system with a diode bridge rectifier and a PWM inverter," IEEE Trans. Ind. Appl., Vol. 39, No. 5, p. 1287-1293, Sep./Oct. 2003.

[4] M. Centner and U. Schafer, "Optimized design of high-speed induction motors in respect of the electrical steel grade," IEEE Trans. Ind. Electron., Vol. 57, No. 1, pp. 288-295, Jan. 2010
[5] R. Ueda, T. Sonoda, K. Koga, and M. Ichikawa, "Stability analysis in induction motor driven by $\mathrm{V} / \mathrm{f}$ controlled general purpose inverter," IEEE Trans. Ind. Appl., Vol. 28, No. 2, pp. 472-481, Mar./Apr. 1992.

[6] A. Munoz-Garcia, T. A. Lipo, and D. W. Novotny, "A new induction motor V/f control method capable of high-performance regulation at low speeds," IEEE Trans. Ind. Appl., Vol. 34, No. 4, pp. 813-821, Jul./Aug. 1998.

[7] B. Wu, High-Power Converter and AC Drives, Wiley Inter-Science, pp. 309-317, 2006.

[8] C. Mastorocostas, I. Kioskeridis, and N. Margaris, "Thermal and slip effects on rotor time constant in vector controlled induction motor drives," IEEE Trans. Power Electron., Vol. 21, No. 2, pp. 495-504, Mar, 2006.

[9] H. A. Toliyat, M. S. Arefeen, K. M. Rahman, and D. Figoli, "Rotor time constant updating scheme for a rotor flux-oriented induction motor drive," IEEE Trans. Power Electron., Vol. 14, No .5, pp. 850-857, Sep. 1999.

[10] D. Telford, M. W. Dunnigan, and B. W. Williams, "Online identification of induction machine electrical prarmeters for vector control loop tuning," IEEE Trans. Ind. Electron., Vol. 50, No. 2, pp. 253-261, Apr. 2003.

[11] S. Maiti, C. Chakraborty, Y. Hori, and M. C. Ta, "Model reference adaptive controller-based rotor resistance and speed estimation techniques for vector controlled induction motor drive utilizing reactive power," IEEE Trans. Ind. Electron., Vol. 55, No. 2, pp. 594-601, Feb. 2008.

[12] A. Ba-Razzouk, A. Cheriti, and P. Sicard, "Implementation of a DSP based real-time estimator of induction motor rotor time constant," IEEE Trans. Power Electron., Vol. 17, No. 4, pp. 534-542, Jul, 2002.

[13] S. Wade, W. Dunnigan, and B. W. Williams, "A new method of rotor resistance estimation for vector-controlled induction machines," IEEE Trans. Ind. Electron., Vol. 44, No. 2, pp. 247-257, Apr. 1997.

[14] D. P. Marcetic and S. N. Vukosavic, "Speed-sensorless AC drives with the rotor time constant parameter update," IEEE Trans. Ind. Electron., Vol. 54, No. 5, pp. 2618-2625, Oct. 2007.

[15] K. Wang, B. Chen, G. Shen, W. Yao, K. Lee, and Z. Lu, "Online updating of rotor time constant based on combined voltage and current mode flux observer for speed-sensorless AC drives," IEEE Trans. Ind. Electron., Vol. 61, No. 9, pp. 4583-4593, Sep. 2014.

[16] F. Salmasi and T. Abbasian, "An adaptive observer with online rotor and stator resistance estimation for induction motors with one phase current sensor," IEEE Trans. Energy Convers., Vol. 26, No. 3, pp. 959-966, Sep. 2011.

[17] G. Kenne, R. S. Simo, F. L. Lagrrigue, A. Arzande, and J. C. Vannier, "An online simplified rotor resistance estimator for induction motors," IEEE Trans. Contr. Syst. Technnol., Vol. 18, No. 5, pp. 1188-1194, Sep, 2010.

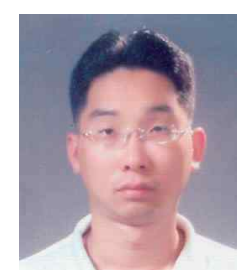

Anno Yoo was born in Korea, in 1977. He received his B.S., M.S., and Ph.D. in Electrical Engineering from Seoul National University, Seoul, Korea, in 2004, 2006, and 2010 , respectively. Since 2010, he has been a Senior Research Engineer with LSIS Co., Ltd., Anyang, Korea. He is the holder of 4 registered patents in the U.S.A. and Japan, and he has 62 pended patents in various countries. His current research interests include high-performance ac drive systems and high-power converters for grid-connections. 